\title{
Strategic interaction between inter vivos gifts and housing acquisition
}

\author{
Norifumi Yukutake \\ Housing Research \& Advancement Foundation of Japan, 6-3 Nibancho, Chiyoda, Tokyo 102-0084, Japan \\ Shinichiro Iwata* \\ Faculty of Economics, University of Toyama, 3190 Gofuku, Toyama, Toyama 930-8555, Japan \\ Takako Idee \\ Faculty of Economics, Seikei University, 3-3-1 Kichijojikitamachi, Musashino, Tokyo 180-8633, Japan
}

\begin{abstract}
This paper models the interdependence of parental inter vivos gifts and children's home purchases when informal care affects decision making. We use data from Japanese households who purchased a detached house in an urban area to test this strategic interaction. Considering both censoring and endogeneity of inter vivos gifts, which are identified by information on formal care, our preferred results demonstrate that inter vivos gifts do not significantly increase the purchase price of housing. Theory suggests that this occurs when informal care tends to be a heavy burden for children. However, subsample analysis of young home buyers indicates that the empirical results are consistent with the literature: children who receive parental gifts tend to purchase a higher-priced dwelling. One potential explanation is that relatively young adult children are less likely to take charge of care obligations, and accordingly, parental gifts are only expected to relax their liquidity constraints. Subsample analysis appears to indicate that the underlying motivation of parental gifts is influenced by the timing of children's home purchase decisions.
\end{abstract}

JEL classification: D11, D12, J14, R21

Key words: Intergenerational transfer, home purchase, exchange motive, informal care

\footnotetext{
${ }^{*}$ Corresponding author. E-mail address: iwata@eco.u-toyama.ac.jp (S. Iwata)
} 


\section{Introduction}

As a conventional mortgage requires approximately 20 percent down payment on a loan, homebuying households must build up substantial savings; therefore, down payment constraints may distort the optimal housing consumption (Artle and Varaiya 1978). Parental gifts are expected to relax this borrowing constraint. Indeed, previous studies have demonstrated that inter vivos gifts by parents to their adult children play an important role in increasing down payments and raising the value of the acquired house (Engelhardt and Mayer 1998; Guiso and Jappelli 2002; Zhou 2007; Luea 2008; Spilerman and Wolff 2012).

The claim that inter vivos gifts encourage housing demand seems to be induced from rational behavior. This can be true when parents have an altruistic preference: an increase in parental gifts only has an impact similar to an increase in income for home purchases. Parental gifts are simply used to increase the well-being of children from the children's point of view; therefore, children tend to purchase a higher-priced dwelling. The question is then whether or not parents freely provide inter vivos gifts even in the aging societies that most developed countries are facing. In such a society, parents may provide financial transfers in exchange for receiving informal care. That is, inter vivos gifts are not always available for children to finance dwelling purchases. Accordingly, the effect of inter vivos gifts on housing consumption becomes more complex.

Although substantial inter vivos gifts are implicitly associated with informal care and are frequently earmarked for home purchases, empirical evidence on this issue is limited to date. This may reflect the fact that even though researchers obtain information on the value of inter vivos gifts and housing consumption, they cannot obtain information on informal care. Our data set appears to face the same problem. To overcome this problem, we use publicly available information on formal care, which is a substitute for informal care to some extent (Van Houtven and Norton 2004).

A theoretical model of strategic interaction between inter vivos gifts and the home purchase price leads to an empirical model where the home purchase price is a function of the value of 
inter vivos gifts, which depends on formal care. Our theory suggests that inter vivos gifts do not always increase the purchase value of an acquired house. To test this hypothesis, we use a repeated cross section of households who purchased a detached house in an urban area of Japan. Japanese evidence may provide interesting insights. In Japan, home ownership rates of younger generations have been declining substantially, potentially because economic stagnation has deteriorated the employment situation among young people. Inter vivos gifts thus seem to be particularly important for children in home purchases. On the other hand, older generations have accumulated a large portfolio of financial assets to fund their postretirement lives. Parents used to use a certain amount of these funds as rewards for informal care provided by children (Izuhara 2004). ${ }^{1}$ Therefore, exchange tends to be the traditional and primary motive for transfers from parents to children in Japan. Japan, however, faces the most rapid growth in the proportion of elderly in the population in the world. Reflecting the heavy burden of informal care, a social insurance scheme for long-term care has been designed to promote the formal care market (Izuhara 2004; Abe 2009). This indicates that parents can consider formal care, which may substitute for informal care, when they decide the value of inter vivos gifts.

As a benchmark, we examine the impact of inter vivos gifts on home values, using OLS. The empirical results are consistent with parents' behaving in an altruistic way: the prices of homes purchased are positively associated with inter vivos gifts. However, there may be a problem of potential endogeneity of inter vivos gifts because of omitted variables such as the liquidity constraints of children, which have an impact on both children's and parents' behavior. From our theory, we use proxy variables of formal care that appear to affect the value of inter vivos gifts for identification to deal with this endogeneity. Indeed, our empirical results indicate that inter vivos gifts are significantly affected by formal care. In addition to the possible endogeneity, we must account for censoring of inter vivos gifts, because observations of inter vivos gifts are limited to values greater than or equal to zero. Considering these two issues, our empirical results demonstrate that inter vivos gifts have no significant effect on the

\footnotetext{
${ }^{1}$ Japanese Civil Law may justify this. According to this Civil Law, a successor who has made substantial contributions to the maintenance, or to the increase in the value, of the predecessor's estate through medical treatment or nursing of the predecessor, or by other means, is entitled to receive a gift of greater value than his/her legal portion of an inheritance. This is called a contributory portion.
} 
purchase price. This suggests that exchange is an additional motive to consider regarding the relationship between inter vivos gifts and housing acquisition.

Subsample analysis, however, indicates that differences in parental transfer motives exist between the two subgroups. We examine the subsamples that categorize children into two groups: householders aged below 35 years and householders aged 35 years and over. Even when we consider endogeneity and censoring of inter vivos gifts, the empirical results demonstrate that parental gifts have a significant positive impact on housing demand for children who are relatively young, a finding that is inconsistent with the above results. Namely, parents' behavior is based on a relatively weak exchange motive for this subgroup, but not for the other subgroup. The underlying motivation of parental gifts tends to be influenced by the timing of children's home purchases in the life course.

\section{Literature review}

\subsection{Inter vivos gifts and exchange}

Altruism is one of the well-known explanations of patterns of wealth transfer from parents to their adult children (Becker 1974). According to the altruism model, parents care about the well-being of their children, and they are more likely to leave their assets to the children who have less income. Bernheim et al. (1985) suggested that in addition to altruism, exchange is another motive for bequest. In their theoretical model, parental bequest is used to influence the amount of attention provided by children. Namely, children agree to provide attention to their parents in exchange for receiving a bequest. Controlling for the endogeneity of parental bequests by the parents' lifetime earnings, the empirical results of the 2SLS appear to support their hypothesis: attention, which is measured by visiting and making phone calls, is positively affected by parental bequest.

Cox (1987) used inter vivos transfers to examine the exchange motive for intergenerational transfers instead of bequest wealth, because the majority of private income transfers occur between living persons in the US. Different from the altruism case, in the case of exchange, parents potentially increase transfers to induce attention from wealthy children if there are no 
close market substitutes for attention. Indeed, both the Probit and the Tobit models, which consider the censoring of inter vivos gifts, suggest that inter vivos gifts are positively related to children's income.

Norton and Van Houtven (2006) argued that parents are more likely to use inter vivos gifts than bequests for exchange. One of the reasons is that inter vivos gifts can be adjusted quickly to the amount of informal care and attention. In the empirical analysis, informal care was the focus because it tends to be easier to measure and may involve more of the children's effort and time. They examined the reverse causation inherent in inter vivos transfer and informal care, and used the Logit model with household fixed effects to control for the endogeneity bias of informal care. The results suggested that, as expected, children who provide informal care appear to receive larger inter vivos transfers. Using different longitudinal surveys in the US, Norton et al. (2013) found qualitatively similar results.

\subsection{Inter vivos gifts and housing demand}

Previous empirical evidence has suggested that parental inter vivos gifts have a positive impact on children's housing demand. Engelhardt and Mayer (1998) analyzed the impact of transfers targeted for first-time home buyers based on a repeated cross section of households in 18 major US cities. A housing down payment and mortgage debt were modeled as functions of transfers. The OLS estimates indicated that transfers increase the down payment and increase the mortgage debt. They then concluded that transfer recipients are likely to increase the value of the home that they purchase, because the home value is defined as the sum of the down payment and the mortgage debt.

Guiso and Jappelli (2002) used a retrospective cross section of both home owners and renters in Italy. Treating renters as censored observations, they estimated the home value function using a Tobit regression model. Similar to Engelhardt and Mayer (1998), they found that bequests and inter vivos gifts allow households to purchase more expensive homes. They suggested that transfers have a strong positive effect on the value of homes purchased, because over two-thirds of gifts are received in the year preceding the purchase in their sample. 
Luea (2008) examined separately the impacts of financial help and inter vivos gifts on home values. She hypothesized that financial help, which is received more frequently and in smaller increments, is expected to have a smaller impact on home values than inter vivos gifts, which are received as large lump sums. She estimated the home value function using a random effects model based on US household-level panel data for both first-time and existing home owners. The empirical results supported her hypothesis: financial help does not have a significant impact on home values, while inter vivos gifts do have a positive and significant impact.

Spilerman and Wolff (2012) examined the consequences of parental transfers for the down payment proportion and the home value. Using a cross section of homeowners in France, they estimated a home value function by OLS. Their empirical results indicated that both the incidence and amount of inter vivos gifts received before the home purchase increase the home value of adult children. Using respondents who have never purchased a home, they also demonstrated that transfers before a home purchase increase the down payment proportion. On the other hand, the coefficients of both the incidence and amount of inter vivos gifts received after a home purchase have a negative and insignificant effect, indicating that they have no impact on the home value. They also showed, using descriptive statistics, that children who receive a large transfer are less likely to reduce nonhousing consumption expenditures. This appears to indicate that parental transmissions earmarked for a home purchase can have spillover effects to other aspects of living standards.

The studies mentioned above that focus on the effect of inter vivos gifts on housing demand have given little attention to the motives behind parental transfer decisions. Cirman (2008), however, examined the hypothesis that if the motives for intergenerational transfers earmarked for housing acquisition are related to liquidity constraints, then their incidence is tied to the conditions in the housing market and the market for housing finance. To test the hypothesis, she used a telephone interview of Slovenian households, where the dependent variable in a linear regression model is the incidence of transfers received from their families to acquire housing, and the independent variables relate to the housing market such as interest rates and housing prices. The empirical results demonstrated that intergenerational transfers for acquiring a 
residential property increase when both housing prices and interest rates are relatively high. From this, she concluded that transfers can act as an informal source of housing finance and can play a cushioning role in harsh market conditions. This suggests that parents are altruistic, and therefore parents help their children when they are confronted with unfavorable housingrelated conditions.

Zhou (2007) used visiting as an instrument to consider the endogeneity of intergenerational transfers. She employed a cross section of couples who have preschool children from six Japanese prefectures. The Tobit model indicated that visiting has a significantly positive impact on the amount of intergenerational transfers, which is consistent with exchange. She then regressed the down payment and the home value on the predicted amount of intergenerational transfers. The empirical results, however, were similar to those of previous studies in which the house value and the down payment tend to increase with increases in the predicted generational transfers.

In sum, the literature has appeared to arrive at a consensus that parental gifts raise the home value of children, except in the case of gifts received after home purchase derived from Spilerman and Wolff (2012).

\section{The model}

The purpose of this section is to develop a theoretical model that considers the observable characteristics in our empirical study. The theory leads to testable hypotheses and informs the empirical work. There are two players in the model: a donor, say the parent, and a recipient, the child. The parent is assumed to be imperfectly altruistic: the parent cares for the utility of the child, whereas the parent cares about services that the child may provide. On the other hand, the child is assumed to be nonaltruistic. We adopt the following two-stage framework: the parent first decides how much to give in terms of nonnegative inter vivos gifts $g$ to the child, and an amount of formal care $m$ in the market. The child then decides a consumption of housing $h$ and composite good $x$, given the size of gifts made by the parent. Our model applies a simple noncooperative game framework with a Stackelberg equilibrium that can examine 
strategic interaction between $g$ and $h$. As mentioned in Section 1, one of the reasons that gifts are provided by the parent is the exchange motive: the child provides services in exchange for $g$. The literature has suggested that services may include both attention and informal care, whereas we assume that services measure only the level of informal care $s$. Norton and Van Houtven (2006) and Norton et al. (2013) also focused only on informal care, because it can be measured easily. Our main concern, however, is that we cannot observe informal care from our data. To consider this issue, we assume that the parent directly controls $s$ using inter vivos gifts $g$. Namely, if the child agrees to receive a nonnegative value of $g$, then in exchange, the child must provide positive $s$. We suppose that $s$ is given as an increasing linear function of $g$ : $s=s(g), \underline{s}=s(0)$, and $s_{g}>0, s_{g g}=0$, where $\underline{s}$ indicates the constant and minimum level of informal care regardless of $g$, and the subscripts indicate the first and second derivatives. The implication of Bernheim et al. (1985) is that an increase in gifts increases services: $s_{g}>0$. We believe that this assumption may capture the essence of exchange. On the other hand, the literature has suggested that there are generally no market substitutes for a child's services. Empirical evidence in the health economics literature, however, has demonstrated that informal care by the child is a substitute for formal care such as nursing home care and hospital care (Van Houtven and Norton 2004). Following this evidence, we explicitly consider $m$ as a choice variable for the parent.

Assume that the utility function of the child depends on $h, s$, and $x$. We assume that the price of housing is normalized to 1 , because we can only observe the purchase price from the data. This implies that $h$ is expressed in terms of monetary amounts. Note that Guiso and Jappelli (2002) treated renters as censored observations $(h=0)$. However, we do not have this information, and consequently we only consider the case where $h>0$. Because we focus mainly on $h$ and $s$, the utility function of the child is assumed to be separable as follows:

$$
U=u(h, s)+\mu(x)
$$

Both $h$ and $x$ are assumed to increase subutility at a decreasing rate: $u_{h}>0, u_{h h}<0, \mu_{x}>0$, and $\mu_{x x}<0$. We assume that the child derives disutility from nursing services at a decreasing 
rate; namely, $u_{s}<0$ (Cox 1987) and $u_{s s}<0$.

The budget constraint of the child becomes:

$$
y_{C}+g=h+p x
$$

where $y_{C}$ is the income of the child, and $p$ is the price of the composite. The inter vivos gift is only intended for a housing acquisition in the data used in the empirical section. To avoid the corner solution, we assume that the inter vivos gift does not impose a binding constraint. This adds an extra constraint that a solution of $h$ is larger than $g: h>g$. Indeed, 99.7 percent of a sample that we will use in the empirical part suggests $h>g$. To repeat, $s$ is not the choice variable for the child. Substituting $s=s(g)$ and the budget constraint into the utility function Eq. (1) yields the result that the choice variables are reduced to only one variable: $h$. Solving this unconstrained utility maximization problem, we have the following home value function:

$$
h=h\left(g, y_{C}, p\right) \text {. }
$$

The primary variable of interest is $g$. Differentiating the home value function with respect to a given amount of inter vivos gift, we obtain:

$$
\frac{\partial h}{\partial g}=\frac{\partial h}{\partial y_{C}}-\frac{u_{h s} s_{g}}{U_{h h}}
$$

where $U_{h h}\left(U_{h h}<0\right)$ is the second-order condition for $U$.

As usual, the sign $\partial h / \partial g$ depends on the assumed sign of derivative of the marginal utility of housing with respect to informal care $u_{h s}$. First, let us suppose that $u(h, s)$ is additively separable. This implies $u_{h s}=0$. Then, inter vivos gifts unambiguously raise the house value because the first term of the right-hand side of Eq. (4) is positive, while the second term is zero. Namely, an increase in $g$ has a similar impact to an increase in income. Second, let us relax the separability assumption and replace it with the more plausible assumption of a negative mixed partial derivative of utility with respect to housing and service, $u_{h s}<0$. The negative sign of $u_{h s}$ implies that if there is an increase in the unpleasant care burden, then the marginal utility of the home value decreases. Plausible justification for this assumption is that the marginal utility of housing is decreasing in informal care because relaxing at home is 
less comfortable when it interferes with caring for parents (Victorio and Arnott 1993). In this case, inter vivos gifts do not always increase the house value: an increase in $g$ has a negative impact on $h$ through the child's utility function (the second term). Similar to the first case $\left(u_{h s}=0\right)$, an increase in $g$ still has a positive impact on $h$ through the budget constraint (the first term). As a result, $g$ has an ambiguous impact on $h$.

Consider a case where $\partial h / \partial g \leq 0$. Then subutility $u(h, s)$ decreases when the child receives parental gifts, because an increase in $g$ increases $s$, while it does not increase $h$. The child, however, can increase the subutility $\mu(x)$ by receiving $g$. Indeed, we restrict our analysis to the case where the increment of $\mu(x)$ is larger or at least equal to the reduction in $u(h, s)$ by obtaining $g$, which we discuss later (see Eq. 7).

Now, we consider parental behavior. The private utility function of the parent depends on $s$ and $m$. Because the income of the parent is not observed from the data, the private utility is assumed to be quasilinear: $v(s)+m$. Informal care provided by the child is assumed to increase utility at a decreasing rate. Therefore, $v_{s}>0$, and $v_{s s}<0$. Because the parent cares about the child's utility $U$, the parent's utility function can be assumed as:

$$
V=v(s)+m+u(h, s)+\mu(x) .
$$

Let $y_{P}$ be the income of the parent, and let $q$ be the price of formal care. The budget constraint of the parent is then becomes:

$$
y_{P}=g+q m \text {. }
$$

The parent must ensure that the child receives a nonnegative benefit from obtaining parental gifts in order to be willing to supply informal care. This implies that the partial derivative of the child's indirect utility function with respect to $g$ is nonnegative. The change in $g$ directly affects $u$ and $\mu$, and affects $h$ (see Eq. 3), which in turn affects $u$ and $\mu$. Note that, however, the latter indirect effect drops out, because $h$ is chosen optimally by the child (the envelope theorem). Eventually, the condition of receiving gifts can be written as follows:

$$
u_{s} s_{g}+\mu_{x} \frac{1}{p} \geq 0 .
$$


The parent faces the following five constraints: nonnegative inter vivos gifts $g \geq 0, s=s(g)$, the child's budget constraint Eq. (2), the home value function Eq. (3), the parent's budget constraint Eq. (6), and the condition of receiving gifts Eq. (7).

Substituting $s=s(g)$, Eqs. (2), (3), and (6) into the utility function Eq. (5) yields the result that the choice variables are reduced to only one variable: $g$. Suppose $V_{g g}<0$ for the the second-order condition of a maximum. Then, the optimal value of the gift satisfies:

$$
v_{s} s_{g}-\frac{1}{q}+\left(u_{s} s_{g}+\mu_{x} \frac{1}{p}\right) \leq 0
$$

Note that we only consider the case where the bracket on the left-hand side of Eq. (8) is nonnegative in the form of Eq. (7). Then, the optimal amount of the gift is zero when Eq. (8) holds with inequality (corner solution), while it is positive when Eq. (8) holds with equality.

Solving the unconstrained utility maximization problem, we obtain the gift function. Because of the additive separable form, the gift function only depends on $q$ when Eq. (7) is binding. On the other hand, when Eq. (7) is not binding, the gift function has the general form:

$$
g=g\left(y_{C}, p, q\right)
$$

We are interested in the partial derivative of the price of formal care $q$. Because the private utility function of the parent is assumed to be quasilinear and the formal care $(m)$ is assumed to be a substitute for the informal care $(s)$, a rise in the price of formal care unambiguously increases the amount of inter vivos transfers. Thus, $\partial g / \partial q>0$. This result suggests that the parent must depend on informal care when the market for formal care is limited. Then, the assumption of a contract to exchange the gift for informal care may become a real possibility.

\section{Empirical analysis}

\subsection{The empirical model}

Our data, which are introduced later, are based on a survey of children's households $i$. For the benchmark, the following linear from of the home value function is estimated by OLS: 


$$
h_{i}=\gamma_{C} g_{i}+X \beta_{C}+\varepsilon_{C i}
$$

where $h_{i}$ is the observed purchase price of the house, $g_{i}$ is the observed value of the inter vivos gift, which is the primary variable of interest, $X$ is a vector of explanatory variables, $\gamma_{C}$ and $\beta_{C}$ are coefficients, and $\varepsilon_{C i}$ is an error term. Instead of $g_{i}$, we also consider $G_{i}$, which is the observed zero-one dummy. The literature has suggested that the sign of $\gamma_{C}$ is likely to be positive. Eq. (4) in the theoretical section, however, indicates that $\gamma_{C}$ may incorporate both the positive effect through the budget constraint and the negative effect through the utility function $\left(u_{h s}<0\right)$, consequently the sign of $\gamma_{C}$ is ambiguous. Explanatory variables include household income $\left(y_{C i}\right)$ and consumer price index $\left(p_{i}\right)$, which are presented in Eq. (3). Following the literature, we also control household characteristics (householder's age and land endowment), regional-specific effect (location dummy), and time-specific effect (year dummy). Note that we focus on $h_{i}>0$, because our data do not include $h_{i}=0$. Spilerman and Wolff (2012) also used only $h_{i}>0$ to capture the impact of intergenerational transfers on housing consumption. Although their data include renters $\left(h_{i}=0\right)$, they excluded renters from the sample because transfers earmarked for a home purchase are not defined for them.

We, however, suspect that the $\gamma_{C}$ coefficient estimated in Eq. (10) is likely to be biased due to the endogeneity of the inter vivos gifts, which arises from the prospect of omitted variables (see also Zhou 2007). In the theoretical section, we only consider the observable characteristics in our dataset. There are, however, unobservable characteristics that affect parent-child behavior but are omitted from both Eqs. (3) and (10). For example, liquidity constraints of children generally have a negative impact on housing consumption. An amount of assets held by children could be a suitable proxy variable of liquidity constraints. The amount of assets, however, is not available in our dataset. From an econometric point of view, the OLS estimator of $\gamma_{C}$ in Eq. (10) does not properly reflect Eq. (4), i.e. $\gamma_{C}$ is biased, if omitted variables and inter vivos gifts are correlated. Nonzero correlation among these variables may exist because our theoretical model indicates that parental gifts respond to all factors affecting housing consumption when children receive a positive benefit from obtaining parental gifts 
(Eq. 9). In fact, McGarry (1999) suggested that children are more likely to receive inter vivos gifts if they are liquidity constrained. If one were to neglect the positive correlation between parental gifts and liquidity constraints of children, the OLS estimator of $\gamma_{C}$ is biased upwards. To account for such endogeneity, we use the IV method. Our theoretical model informs us that the price of formal care $q_{i}$ seems to be a valid variable for identification. On the one hand, $q_{i}$ is expected to have an influence on parental gifts (through Eq. 9), because formal care substitutes for informal care. On the other hand, $q_{i}$ may have only indirect impacts on the purchase price through $g_{i}$, because children tend to care about informal care (that controlled by gifts) rather than formal care (Eq. 3 does not depend on $q_{i}$ ).

We must account for the fact that optimizing behavior leads to a corner solution response for some significant fraction of parents. Namely, observations of inter vivos gifts are limited to values greater than or equal to zero (Eq. 8). To address this censoring issue, the literature has estimated both the Probit and Tobit models: the Probit model is used to analyze the extensive margin (the propensity to transfer), whereas the Tobit model is used to consider the incentive margin (the amount of transfer) (Cox 1987; Auten and Joulfaian 1996; Laitner and Ohlsson 2001; Zhou 2007; Norton et al. 2013). Eventually, the gift value function Eq. (9) is assumed to take the following linear form:

$$
g_{i}^{\#}=\delta_{P} q_{i}+X \beta_{P}+\varepsilon_{P i}
$$

where $g_{i}^{\#}$ is an unobserved latent variable measuring parental gifts, $\delta_{P}$ and $\beta_{P}$ are coefficients, and $\varepsilon_{P i}$ is the error term. ${ }^{2}$ Then in the Probit model, the latent variable determines the outcome observed for the zero-one dummy $G_{i}$ :

$$
\begin{aligned}
G_{i} & =1, \text { if } g_{i}^{\#}>0 \\
& =0, \text { otherwise. }
\end{aligned}
$$

\footnotetext{
${ }^{2}$ As we mentioned in the theoretical section, the income of the parent, which may have an impact on inter vivos gifts, is not available from the data. The exclusion of this variable tends to worsen the goodness of fit of the gift value function.
} 
On the other hand, in the Tobit model, the nonnegative value $g_{i}$ is defined as follows:

$$
\begin{aligned}
g_{i} & =g_{i}^{\#}, \text { if } g_{i}^{\#}>0 \\
& =0, \text { otherwise. }
\end{aligned}
$$

In this analysis, we employ the following IV procedure. In the first stage, $g_{i}^{\#}$ is estimated by either a Probit model or Tobit model. In the second stage, we use the fitted value of gifts from the first-stage model, Eq. (11), as a generated instrument variable for the observed value of gifts $g_{i}$ in Eq. (10). Consistent with the theoretical analysis, the procedure only allows the instrumented value of gifts in Eq. (10) to take nonnegative values.

\subsection{The data}

The data come from the customer survey conducted by the Japan Federation of Housing Organizations (JHO). Its members consist of various housing suppliers in Japan. ${ }^{3}$ The JHO distributes a questionnaire to home builders whose customers bought a newly custom-built detached house in the three major metropolitan areas of Tokyo, Nagoya, and Osaka, and the four provincial cities of Sapporo, Sendai, Hiroshima, and Fukuoka. The Tokyo metropolitan area includes Saitama, Tokyo Metropolitan, Chiba, and Kanagawa prefectures; the Nagoya metropolitan area includes Gifu, Aichi, and Mie prefectures; and the Osaka metropolitan area includes Kyoto, Osaka, Hyogo, and Nara prefectures. Although the observations are limited to the above areas, according to the Housing Starts (2001-2009) issued by the Ministry of Land, Infrastructure, Transport and Tourism (MLIT), the number of newly built owner-occupied houses accounts for approximately 51.0 percent of such houses in Japan. Home builders do ask their customers to report the transfer amount earmarked for home purchase (this is treated as parental gifts in this paper), the total earned income of household members, and the price paid for the property. The JHO conducts this survey every year and collects individual crosssectional data on approximately 3,000 home-buying households. We use the data from 2001

\footnotetext{
${ }^{3}$ Enterprises of various sizes are members of the JHO: not only large enterprises but also medium and small enterprises. Various kinds of construction methodologies for housing suppliers are also included; e.g., prefabricated construction suppliers, wooden home suppliers, two-by-four home builders, and foreign-designed homes. Details about the JHO are available at http://www.judanren.or.jp/english/index.html (accessed on 17 June, 2014).
} 
to 2009. The number of observations in the full sample is 3,131 in $2001 ; 3,000$ in $2002 ; 3,047$ in $2003 ; 2,794$ in $2004 ; 3,634$ in 2005 ; 3,540 in 2006 ; 3,241 in $2007 ; 3,206$ in 2008 ; and 3,750 in 2009. Screening the data for complete information on the selected variables produces a sample of 27,018 observations, which represents 92.1 percent of the full sample.

Table 1 presents the variable definitions for the endogenous, explanatory, and identification variables. The notations in Table 1 correspond to the notations in the theoretical section.

For the child's income, we use the total annual income before tax earned by all members of a child's household. Home purchases generally tend to rely on permanent income rather than annual income. However, because we cannot observe permanent income, permanent income is proxied by annual income. For the price of the composite good $(p)$, we calculate the regional CPI data in each year by multiplying the nationwide CPI and the regional differences in the index of consumer prices, which are obtained from the Statistics Bureau in the Ministry of Internal Affairs and Communications. Note that both the regional and the nationwide CPI do not include imputed rents of owner-occupied housing.

The price of informal care, $q$, plays the important role of identifying the home value function. There are, however, the following two problems in obtaining this variable. First, we cannot obtain the parents' residential location from the data. We thus assume that children and parents reside in the same region. According to the 2004 wave of the Keio Household Panel Survey, sponsored by the Ministry of Education, Culture, Sports, Science and Technology, approximately 80 percent of senior parents and adult children dwell in the same prefecture in Japan. ${ }^{4}$ Second, we must find market substitutes for informal care. In this paper, we consider the long-term care (LTC) services provided by the market. However, we cannot obtain the market price of LTC, because it is controlled by the government. Instead, we use the capacity of LTC institutions in each prefecture, which is obtained from the Survey of Institutions and Establishments for Long-term Care (Ministry of Health, Labor and Welfare). Izuhara (2006) suggested that LTC institutions are unevenly distributed across the country, which results in a shortage of such institutions in some regions. Therefore, LTC institutions may ensure sufficient

\footnotetext{
${ }^{4}$ The Keio Household Panel Survey is available at http://www.pdrc.keio.ac.jp/en/ (accessed on 17 June, 2014).
} 
variation. From the definition in Table 1, the numerator (number of hospital beds) may reflect the supply side for market care services, while the denominator (elderly population) may reflect the demand side for them. LTC capacity thus probably proxies the accessibility of formal care. Contrary to the expected sign of the price of formal care $(q)$, the expected sign of LTC capacity becomes negative. We thus take the inverse of $q$ in Table 1 . In addition to LTC capacity, we consider professional care services in the home in each prefecture, data that are also available from the above survey. We create a variable called home helper, which equals the number of home helpers divided by the elderly population. We include this variable because the LTC insurance system aims to encourage not institutional care but rather home-based care. It is intended that home-based care will provide senior people with care from their family at home with some assistance from professional care service providers.

To reduce the omitted variable bias, we incorporate the age of householders and its squared value into the set of explanatory variables. As mentioned in Section 1, home ownership rates of younger generations have been declining substantially in Japan. According to the 2008 Housing and Land Survey conducted by MLIT, home ownership rates of individuals aged 30 years or less experienced more than a 10 percentage point decline from 1988 to 2008. This suggests that the amount of housing services consumed may also decline for younger generations. In addition, we use a dummy variable for land acquisition in our analysis. Because the purchase price of housing includes the land acquisition cost, children who have already bought land can deduct this cost from the purchase price. We also include four location dummies, comprising: Tokyo area (reference); Nagoya area; Osaka area; and provincial cities. This is because the price of housing generally depends on location, and geographical dummies may control this factor. Finally, because it is beyond the scope of this paper to investigate the full set of reasons, we include year dummies to control for other factors that may affect the values of both gifts and homes. For example, even though the Japanese tax system for inter vivos gifts is very friendly to children receiving gifts from parents because of the relatively large basic exception amount, children must pay tax in some cases. The Japanese government also provides housing incentives such as the mortgage tax deduction (MTD). The MTD allows 
home-buying households to deduct a percentage of their mortgage balance from their income taxes. However, as neither gift taxes nor the amounts of the deduction are reported, we cannot directly control for them.

Table 2 provides summary statistics. The mean home purchase price is approximately 42.55 million yen, which is approximately 0.82 million yen lower than the national average purchase price of custom-built detached houses in the Housing Market Trend Survey (2001-2009, HMTS) issued by the MLIT. Table 2 indicates that approximately 19.0 percent of observations involved a positive gift. The mean gift value is 1.96 million yen, which is approximately 0.80 million yen higher than the national average in the HMTS (2001-2009). The mean children's income is 8.73 million yen, which is 1.54 million yen higher than the mean household's income in the HMTS (2001-2009). The mean householder's age is 42.97 years, which is 0.73 years younger than that in the HMTS (2001-2009).

Table 3 provides the difference in mean values between the respondents who received gifts and those who did not. On average, children's income without a gift is 1.57 million yen higher than for children with a gift. Although children with a gift receive approximately 10 million yen on average, they consume 0.62 million yen less than children without a gift. This suggests that parental gifts tend not to increase the purchase price of housing. Of course, these numbers are simply raw averages and should be treated with caution in relation to other factors and the endogeneity issues mentioned above. Fig. 1, which represents the kernel densities of the home value, also stresses that the exact direction of the effect of gifts on the home value is ambiguous. The solid line refers to the density of the home value with a gift, while the dashed line refers to that of the home value without a gift. Note that we exclude the higher values from this figure by $3 \sigma$ in order to facilitate the comparison of these densities. If gifts have a positive impact on the value of acquired houses, as suggested by the literature, then the home value distribution with gifts shifts rightward. Indeed, Fig. 1 indicates that the higher tail of the distribution with gifts shifts rightward. The lower tail of the distribution, however, shifts leftward. 


\subsection{Estimation results}

Models [1] and [2] in Table 4 provide the OLS estimation results. Model [1] considers the zeroone dummy of inter vivos gifts, whereas model [2] considers their observed value. Both models [1] and [2] indicate that inter vivos gifts have a significantly positive effect on the value of acquired houses, which is consistent with previous studies (Engelhardt and Mayer 1998; Guiso and Jappelli 2002; Zhou 2007; Luea 2008; Spilerman and Wolff 2012). Model [2] indicates that a one million yen increase in gifts increases the value of the home purchased by approximately 0.494 million yen. The following two studies also demonstrated that the increment in home value is less than the gift amount, which is similar to our result. That is, Guiso and Jappelli (2002) found that for each one euro in gifts, home value rises by 0.46 euros, and Luea (2008) found that for each one dollar in gifts, home value rises by 0.20 dollars. The child's income has a positive sign and is significant; therefore, housing consumption is a normal good. The price index suggests that the substitution effect outweighs the income effect, because the coefficient is significant and positive. Therefore, children tend to purchase more expensive housing when housing-related conditions are favorable to them. Age and its squared value indicate that older households spend more on housing at a decreasing rate. As expected, younger households are more likely to purchase less expensive dwellings in Japan. The significantly positive sign of land indicates that households who have already obtained land tend to spend more on housing than others.

Models [3] and [4] in Table 4 report the results of the IV method. We find that the coefficient of the gift dummy in the second stage is statistically insignificant in model [3]. Model [4] demonstrates that a one million yen increment in gifts increases the home value by approximately 0.139 million yen. This impact is smaller than that in model [2] and statistically insignificant. The coefficients of both the gift dummy and gift are statistically insignificant, potentially because the standard errors of the IV estimates (models 3 and 4) are larger than those of the OLS estimates (models 1 and 2). This suggests that LTC capacity and home helper are likely to be weak instruments. We, however, claim that both variables are not weak for the following two reasons. First, as mentioned below, each coefficient is significant in the 
first stage in both models [3] and [4]. Second, each $F$-statistic for joint significance of LTC capacity and home helper is sufficiently larger than the rule of thumb value of 10 , which is the criterion suggested by Staiger and Stock (1997): 32.48 in model [3] and 13.42 in model [4]. In summary, contrary to common belief, these results indicate that adult children do not necessarily increase their housing consumption after they receive parental gifts. This is probably because the positive impact through the budget is reversed by the negative impact through the children's utility $\left(u_{h s}<0\right)$. Namely, an informal care responsibility tends to be quite a burden for children; consequently, parental gifts tied with both informal care and housing acquisition discourage children's demand for housing.

Because inter vivos gifts are intended for home purchases, adult children probably use all of them to increase their down payment and to reduce mortgage debt by the same amount. In the context of Engelhardt and Mayer (1998), this implies that housing consumption, which is the sum of down payment and mortgage debt, is not affected by inter vivos gifts (on page 150). Our theory then suggests that adult children may increase nonhousing consumption by using their income, instead of increasing housing consumption. This result is consistent with Spilerman and Wolff (2012) to some degree, which is shown in Section 2.2.

In the first stage of models [3] and [4] in Table 4, we find that children are statistically more likely to receive parental transfers when their household income is low and when householders are young (the coefficient of age squared is relatively large and negative), which is consistent with the literature (Engelhardt and Mayer 1998; Cirman 2008). The coefficients of LTC capacity, which are associated with the variable for identification, are significant and negative, indicating that children are less likely to receive transfers when seniors' access to LTC institutions is improved. This may suggest that parents can rely on formal care and consequently reduce intergenerational transfers to induce informal care. Moreover, this result may be consistent to some extent with the findings of Izuhara (2004). She suggested that the link between children's support and transfers is increasingly being weakened in Japan. The coefficients of home helper, however, have a significant and positive sign, which runs contrary to our expectation. An explanation of this unexpected result can be found in Abe (2009). 
Abe (2009) claimed that LTC insurance system has reduced the burden on families to a small extent. She demonstrated that professional care services at home only serve as a minor supplement to familial care. This indicates that parents who rely on professional care at home must rely on informal care at home as well, and accordingly transfers being received increase both the extensive and the intensive margins.

\subsection{Subsample analysis}

In this section, we divide the sample into age: householders aged less than 35 years $(<35)$ and those aged 35 years or more $(35+)$, because some papers have considered young adult children. For example, the data used by Engelhardt and Mayer (1998) have an average age that is approximately 10 years younger than our data. Mulder and Smits (1999) limited their analysis to couples up to the age of 40 to ensure some homogeneity in terms of stage of life; young couples are generally still in the process of family formation and career development. Although not explicitly stated, it is likely that Zhou (2007) considered relatively young couples, because the analysis was limited to couples with preschool children.

We again adopt the IV procedure. Only the results of the home value function (the second stage) are reported in Table 5. The coefficient of the gift dummy in model [5] indicates a significant and positive effect on younger children's demand for housing, which differs from model [3] in Table 4. Model [6] also suggests that the coefficient of gift has a significant and positive sign. Namely, a one million yen increment in gifts increases the value of the home purchased by approximately 1.297 million yen. Similar to Engelhardt and Mayer (1998), the effect of an increment in gifts on the purchase price of housing is greater than the amount of gifts. They found for each dollar in gifts, home value rises by 1.34 dollars. The significant and positive impact of gifts on home value may be observed because gifts relax the liquidity constraint involved in purchasing a house. As mentioned, it is difficult for young adults today to get a permanent job (see also Öst 2012). Young adults thus have faced a severe liquidity constraint in purchasing a home. Cirman (2008) suggested that intergenerational transfers are used in such a situation. In other words, parents' behavior is based on a relatively weak 
exchange motive. Because the positive $s_{g}$ reflects the exchange motive of parents in our context, $s_{g}$ is relatively small for young adults in Eq. (4). The other reason that may explain the significant and positive sign relates to $s_{g}$. Parents of younger adult children are less likely to have health deterioration issues, because they are likely to be younger themselves. In this sense, young adults receive parental gifts without the expectation of the heavy burden of informal care, and again $s_{g}$ is relatively small in Eq. (4). Of course, other explanations are possible from Eq. (4): younger adult children are less likely to be in charge of care obligations, and consequently the absolute value of $u_{h s}$ is relatively small; the positive impact of gifts through the budget constraint $\partial h / \partial y_{C}$ may be relatively large for younger adult children. On the other hand, models [7] and [8] suggest that gifts received after middle age have no significant impact on housing consumption, indicating that parents' behavior is based on exchange.

All the signs of the coefficients of child's income and price index in Table 5 are the same as those in models [3] and [4] in Table 4. The signs of the coefficient of age and its squared value in models [5] and [6] are different from those in models [3] and [4] in Table 4, and statistically significant. Because the coefficient of age squared is relatively large and positive, the estimated result in model [6] shows that the purchase price of housing reaches a minimum at approximately 26 years, and then increases until the age of 35 years. On the other hand, the coefficients of age and its squared value in models [7] and [8] are statistically insignificant, suggesting that the value of the home purchased is not affected by the age of the subgroup aged 35 years and over.

\section{Conclusion}

Previous studies in relation to inter vivos gifts and home purchases have paid little attention to the exchange motive of parents and children. In contrast, this paper has assumed that children provide informal care services in exchange for gifts. Theoretical models suggest that inter vivos gifts do not always raise the purchase price of housing. This contradicts the idea of altruism: inter vivos gifts tend to increase the purchase price. The theoretical reason underlying our hypothesis is that the positive impact of gifts on housing consumption through the budget 
constraint is weakened by the negative impact through the utility function of children. In our model, children's marginal utility of housing was assumed to decrease when informal care increases. Because inter vivos gifts were earmarked to be used for housing acquisition in our data, this assumption might be valid to some degree. Namely, children are more likely to hesitate when purchasing a higher-priced dwelling using their parental gifts because gifts are associated with a heavy burden of informal care.

To test our hypothesis, we used data of households who purchased a detached house in an urban area of Japan. Carefully controlling for potential endogeneity of inter vivos gifts, which are identified by information on formal care, and considering censoring of inter vivos gifts, our preferred empirical results indicated that inter vivos gifts do not have a significant impact on the purchase price of housing. Namely, inter vivos gifts appear to have almost no effect, which is consistent with the exchange motive. Moreover, the empirical results demonstrated that inter vivos gifts are significantly affected by formal care. This suggests that variables related to formal care are useful in considering the endogeneity of gifts, which generally have been overlooked by the literature.

We do not intend to argue against altruism as a motivation for providing informal care. In some countries, it is expected by society that children will look after their parents. In relation to this point, suppose that children are altruistic. They may invest a relatively large amount of money in housing and at the same time provide a service for their parents while refusing to receive a large parental gift. Then, inter vivos gifts may also have only small impacts on the home value. Instead, exchange may be an additional motivator in a society where informal care of parents involves the children's lives being substantially burdened. Japanese society indeed has been told that children were on the verge of collapsing under the heavy burden of nursing care for their aged parents (Izuhara 2004).

Even though neither the theoretical model nor the empirical model includes any policy parameters, our result may be useful for evaluating them. For example, to stimulate domestic demand, the Japanese government introduced a tax waiver for children receiving inter vivos gifts for the acquisition of a home, which may encourage parents to donate money to their 
children for the purchase of a higher-priced home. To repeat, however, our preferred empirical results demonstrated that inter vivos gifts have little impact on children's demand for housing.

Subsample analysis suggested that the motivation behind parental gifts tends to be influenced by the timing of children's home purchases in the life course. We found that inter vivos gifts still have no statistically significant effect on the purchase price of housing for children who are relatively old. Yet, parental gifts significantly increase the purchase price of homes of children who are relatively young, even when we consider both censoring and endogeneity of inter vivos gifts. One possible explanation is that parents' behavior is less likely to be based on the exchange motive for young home buyers.

In line with the results of the subsample analysis, we must examine selectivity bias. Because our data only include newly custom-built detached houses, both ready-built detached houses and condominium units are not included. If home buyers who are relatively young prefer such homes, then parental gifts may have a positive impact on the value of the acquired home. This suggests that our conclusion, which used all observations, suffers from sample selection bias toward the null. Nevertheless, the data are meaningful for testing whether exchange is an additional motive to consider in examining the relationship between inter vivos gifts and housing acquisition.

\section{Acknowledgements}

We would like to thank two anonymous reviewers, Lawrence Brown, Toshiyuki Hirai, Daiji Kawaguchi, Wataru Kureishi, Yung Lung Lee, Oleksandr Movshuk, and Michio Naoi, as well as participants in seminars at Hitotsubashi University, Keio University, Konan University, Ritsumeikan University, Tohoku University, and University of Tokyo and conferences at ARSC, AsRES, ENHR, JEA, NAAN, and NARSC for their valuable comments. We are also grateful to the Japan Federation of Housing Organizations for access to microdata. Part of this paper was written while Shinichiro Iwata was visiting Department of Urban Studies, University of Glasgow. He gratefully acknowledges its hospitality. The views expressed here are solely those of the authors and do not reflect any of the institutions they belong to. This research was part of a project of Housing Research \& Advancement Foundation of Japan and supported by the Japan Economic Research Foundation. 


\section{References}

Abe, A. K., 2009. The political and social economy of care: Japan research report 3. United Nations Research Institute for Social Development, Geneva.

Artle, R., Varaiya, P., 1978. Life cycle consumption and homeownership. J Econ Theory 18 (1), 38-58.

Auten, G., Joulfaian, D., 1996. Charitable contributions and intergenerational transfers. J Public Econ 59 (1), 55-68.

Becker. G. S., 1974. A theory of social interactions. J Polit Econ 82 (6), 1063-1093.

Bernheim, B. D., Shleifer, A., Summers, L. H., 1985. The strategic bequest motive. J Polit Econ 93 (6), 1045-1076.

Cirman, A., 2008. Intergenerational transfers as a response to changes in the housing market in Slovenia. Eur J Hous Policy 8 (3), 303-315.

Cox, D., 1987. Motives for private income transfers. J Polit Econ 95 (3), 508-546.

Engelhardt, G. V., Mayer, C. J., 1998. Intergenerational transfers, borrowing constraints, and saving behavior: evidence from the housing market. J Urban Econ 44 (1), 135-157.

Guiso, L., Jappelli, T., 2002. Private transfers, borrowing constraints and the timing of homeownership. J Money Credit Bank 34 (2), 315-339.

Izuhara, M., 2004. Negotiating family support? The 'generational contract' between longterm care and inheritance. J Soc Policy 33 (4), 649-665.

Izuhara, M., 2006. Changing families and policy responses to an ageing Japanese society. In: Rebick, M., Takenaka, A. (Eds.), The Changing Japanese Family. Routledge, London, pp. $161-177$.

Laitner, J. Ohlsson, H., 2001. Bequest motives: a comparison of Sweden and the United States. J Public Econ 79 (1), 205-236. 
Luea, H. M., 2008. The impact of financial help and gifts on housing demand and cost burdens. Contemp Econ Policy 26 (3), 420-432.

McGarry, K., 1999. Inter vivos transfers and intended bequests. J Public Econ 73 (3), $321-351$.

Mulder, C. H., Smits, J., 1999. First-time home-ownership of couples the effect of intergenerational transmission. Eur Sociol Rev 15 (3), 323-337.

Norton, E. C., Nicholas, L. H., Huang, S. S. H., 2013. Informal care and inter-vivos transfers: results from the National Longitudinal Survey of Mature Women. BE J Econ Anal Poli $14(2), 377-400$.

Norton, E. C., Van Houtven, C. H., 2006. Inter-vivos transfers and exchange. South Econ J $73(1), 157-172$.

Öst, C. E., 2012. Parental wealth and first-time homeownership: a cohort study of family background and young adults' housing situation in Sweden. Urban Stud 49 (10), 21372152.

Spilerman, S., Wolff, F. C., 2012. Parental wealth and resource transfers: how they matter in France for home ownership and living standards. Soc Sci Res 41 (2), 207-223.

Staiger, D., Stock, J. H., 1997. Instrumental variables regression with weak instruments, Econometrica $65(3), 557-586$.

Van Houtven, C. H., Norton, E. C., 2004. Informal care and health care use of older adults. J Health Econ 23 (6), 1159-1180.

Victorio, A. G., Arnott, R. J., 1993. Wealth, bequests and attention. Econ Lett 42 (2), 149-154.

Zhou, Y., 2007. The impact of financial aid of parents on the house purchase behavior of children, Q J Hous Land Econ (Kikan Jyutaku Tochi Keizai) 66, 29-37 (in Japanese). 
Table 1: Definition of variables

\begin{tabular}{|c|c|c|}
\hline Variable & Definition & Notation \\
\hline \multicolumn{3}{|l|}{ Endogenous } \\
\hline Housing & The purchase price of housing, in millions of yen & $h$ \\
\hline Gift dummy & A binary variable indicating that the household receives a positive amount of gifts & $g$ \\
\hline Gift & The value of gifts, in millions of yen & $g$ \\
\hline \multicolumn{3}{|l|}{ Explanatory } \\
\hline Child's income & $\begin{array}{l}\text { The total annual income before tax earned by all household members, in millions of } \\
\text { yen }\end{array}$ & $y_{C}$ \\
\hline Price index & $\begin{array}{l}\text { The regional CPI, which is the product of the CPI }(2005=100) \text { and the regional } \\
\text { difference index of consumer prices (national average set equal to } 100) \text {, percentage }\end{array}$ & $p$ \\
\hline \multicolumn{3}{|l|}{ Identification } \\
\hline LTC capacity & $\begin{array}{l}\text { The capacity of long-term care institutions for senior citizens in each geographical } \\
\text { category, thousands of hospital beds per hundred thousand elderly }\end{array}$ & $1 / q$ \\
\hline Home helper & $\begin{array}{l}\text { The number of home helpers for senior citizens in each geographical category, } \\
\text { thousands of helpers per hundred thousand elderly }\end{array}$ & $1 / q$ \\
\hline \multicolumn{3}{|l|}{ Other control } \\
\hline Age & Age of householder, years & - \\
\hline Land & A binary variable indicating that the household bought land in the last three years & - \\
\hline Tokyo area & A binary variable indicating that the house is located in the Tokyo area (reference) & - \\
\hline Nagoya area & A binary variable indicating that the house is located in the Nagoya area & - \\
\hline Osaka area & A binary variable indicating that the house is located in the Osaka area & - \\
\hline Provincial city & A binary variable indicating that the house is located in one of the provincial cities & - \\
\hline
\end{tabular}

Notes: Geographical category in LTC capacity and home helper corresponding with the prefecture level for three major metropolitan areas

Geographical category in LTC capacity and home helper corresponding with the major cities level are converted to the prefecture level, because they are only observed at the prefecture level

Year dummies are not reported 
Table 2: Descriptive statistics of the full sample

\begin{tabular}{lrrrr}
\hline Variable & Mean & Std. Dev. & Min. & Max. \\
\hline Housing (million yen) & 42.55 & 23.29 & 0.25 & 524.00 \\
Gift dummy (dummy) & 0.19 & 0.39 & 0.00 & 1.00 \\
Gift (million yen) & 1.96 & 6.44 & 0.00 & 310.00 \\
Child's income (million yen) & 8.73 & 6.17 & 0.00 & 210.00 \\
Price index (percent) & 105.27 & 3.55 & 99.09 & 112.61 \\
Age (years) & 42.97 & 11.67 & 20.00 & 92.00 \\
Land (dummy) & 0.44 & 0.50 & 0.00 & 1.00 \\
LTC capacity (1,000 beds/100,000 elderly) & 2.33 & 0.34 & 1.60 & 3.26 \\
Home helper (1,000 person/100,000 elderly) & 1.54 & 0.42 & 0.71 & 2.67 \\
& & & & \\
\hline
\end{tabular}

Notes: Both location dummies and year dummies are not reported

Table 3: Mean for households with and without a gift

\begin{tabular}{lrrc}
\hline Variable & \multicolumn{1}{c}{ Total } & With a gift & Without a gift \\
\hline Housing (million yen) & 42.55 & 42.04 & 42.66 \\
Gift dummy (dummy) & 0.19 & 1.00 & 0.00 \\
Gift (million yen) & 1.96 & 10.49 & 0.00 \\
Child's income (million yen) & 8.73 & 7.45 & 9.02 \\
Observations & & & 21960 \\
\hline
\end{tabular}


Table 4: Estimation results

\begin{tabular}{|c|c|c|c|c|}
\hline \multirow[t]{2}{*}{$\overline{\text { Variable }}$} & \multicolumn{2}{|c|}{ OLS } & \multicolumn{2}{|c|}{ IV } \\
\hline & [1] & [2] & [3] & {$[4]$} \\
\hline \multicolumn{5}{|c|}{ Housing (2nd $s t a g e)$} \\
\hline \multirow[t]{2}{*}{ Gift dummy } & $1.909 * * *$ & - & -4.791 & - \\
\hline & $(0.272)$ & - & $(7.820)$ & - \\
\hline \multirow[t]{2}{*}{ Gift } & - & $0.494 * * *$ & - & 0.139 \\
\hline & - & $(0.047)$ & - & $(0.870)$ \\
\hline \multirow[t]{2}{*}{ Child's income } & $1.562^{* * *}$ & $1.569^{* * *}$ & $1.535^{* * *}$ & $1.559^{* * *}$ \\
\hline & $(0.108)$ & $(0.106)$ & $(0.112)$ & $(0.111)$ \\
\hline \multirow[t]{2}{*}{ Price index } & $1.020^{* * *}$ & $0.985^{* * *}$ & $1.020^{* * *}$ & $1.010^{* * *}$ \\
\hline & $(0.046)$ & $(0.045)$ & $(0.046)$ & $(0.079)$ \\
\hline \multirow[t]{2}{*}{ Age } & $0.532^{* * *}$ & $0.540^{* * *}$ & $0.448^{* * *}$ & $0.517^{* * *}$ \\
\hline & $(0.111)$ & $(0.110)$ & $(0.147)$ & $(0.123)$ \\
\hline \multirow[t]{2}{*}{ Age squared } & $-0.003^{* * *}$ & $-0.003^{* * *}$ & $-0.003^{* *}$ & $-0.003^{* * *}$ \\
\hline & $(0.001)$ & $(0.001)$ & $(0.001)$ & $(0.001)$ \\
\hline \multirow[t]{2}{*}{ Land } & $20.437^{* * *}$ & $20.008^{* * *}$ & $20.502^{* * *}$ & $20.329 * * *$ \\
\hline & $(0.296)$ & $(0.300)$ & $(0.313)$ & $(0.866)$ \\
\hline \multirow[t]{2}{*}{ Constant } & $-107.973^{* * *}$ & $-104.826^{* * *}$ & $-103.238^{* * *}$ & $-106.118^{* * *}$ \\
\hline & $(5.600)$ & $(5.573)$ & (7.801) & $(6.567)$ \\
\hline$R^{2}$ & 0.421 & 0.438 & 0.430 & 0.429 \\
\hline \multicolumn{5}{|l|}{ Gift (1'st stage) } \\
\hline \multirow[t]{2}{*}{ Child's income } & & & $-0.029^{* * *}$ & $-0.455^{* * *}$ \\
\hline & & & $(0.005)$ & $(0.138)$ \\
\hline \multirow[t]{2}{*}{ Price index } & & & $-0.012^{* * *}$ & -0.112 \\
\hline & & & $(0.005)$ & $(0.090)$ \\
\hline \multirow[t]{2}{*}{ Age } & & & $0.016^{*}$ & $0.515^{* * *}$ \\
\hline & & & $(0.009)$ & $(0.198)$ \\
\hline \multirow[t]{2}{*}{ Age squared } & & & $-0.001^{* * *}$ & $-0.012^{* * *}$ \\
\hline & & & $(0.000)$ & $(0.002)$ \\
\hline \multirow[t]{2}{*}{ Land } & & & $0.052^{* * *}$ & $2.419^{* * *}$ \\
\hline & & & $(0.020)$ & $(0.395)$ \\
\hline \multirow[t]{2}{*}{ LTC capacity } & & & $-0.203^{* * *}$ & $-3.081 * * *$ \\
\hline & & & $(0.039)$ & $(0.747)$ \\
\hline \multirow[t]{2}{*}{ Home helper } & & & $0.173^{* * *}$ & $3.633^{* * *}$ \\
\hline & & & $(0.044)$ & $(0.837)$ \\
\hline \multirow[t]{2}{*}{ Constant } & & & $1.376^{* * *}$ & 0.939 \\
\hline & & & $(0.525)$ & $(10.340)$ \\
\hline Log likelihood & & & -12033.16 & -29378.49 \\
\hline
\end{tabular}

Notes: 27,018 observations

Robust standard errors in parentheses

All models are controlled by location and year dummies $* * *, * *, *$ indicate significant at $1 \%, 5 \%, 10 \%$, respectively 
Table 5: The IV estimation results of the subsample

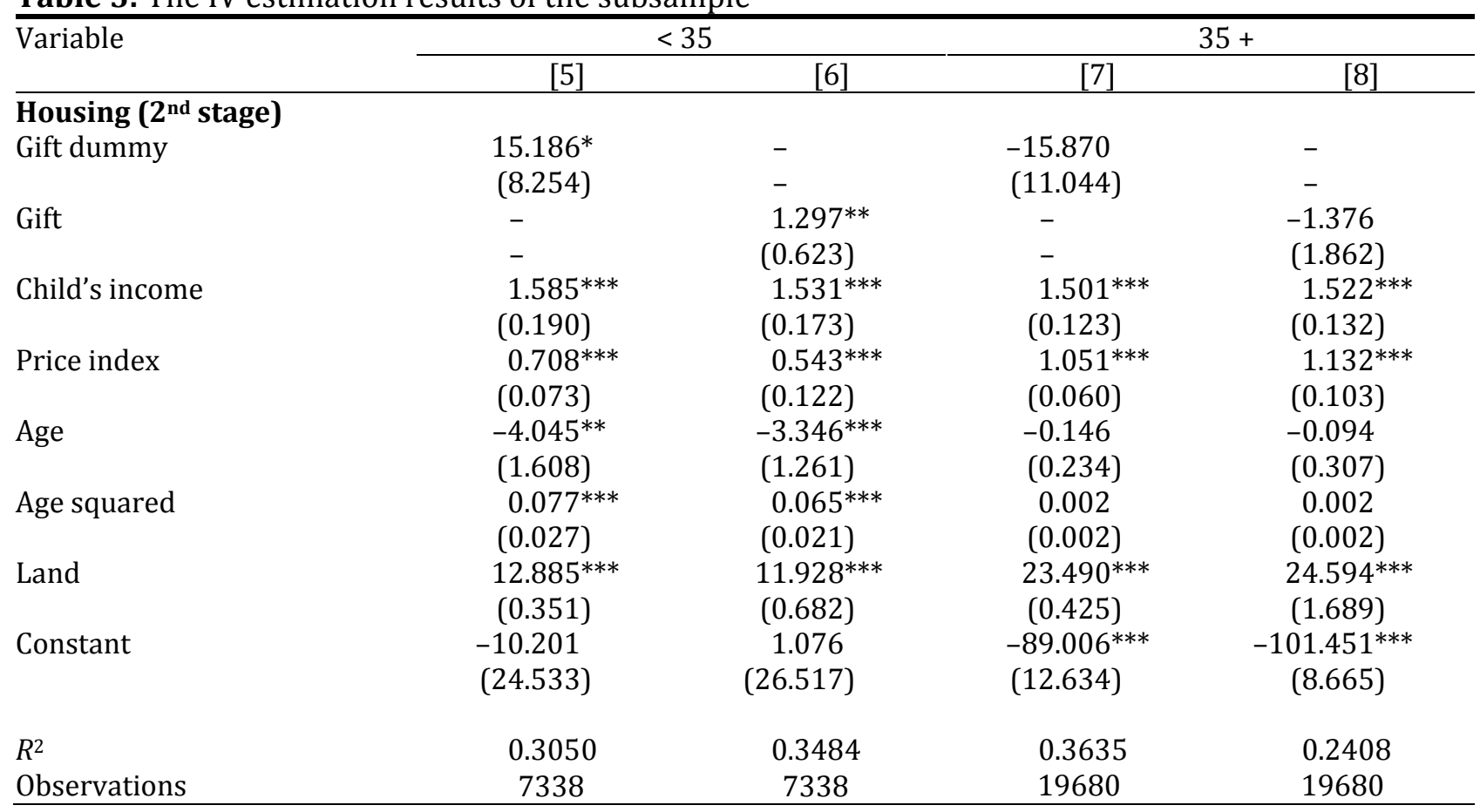

Notes: Robust standard errors in parentheses

All models are controlled by location and year dummies

The results of the gift value function ( $1^{\text {st }}$ stage) are not reported

$* * *, * *, *$ indicate significant at $1 \%, 5 \%, 10 \%$, respectively 


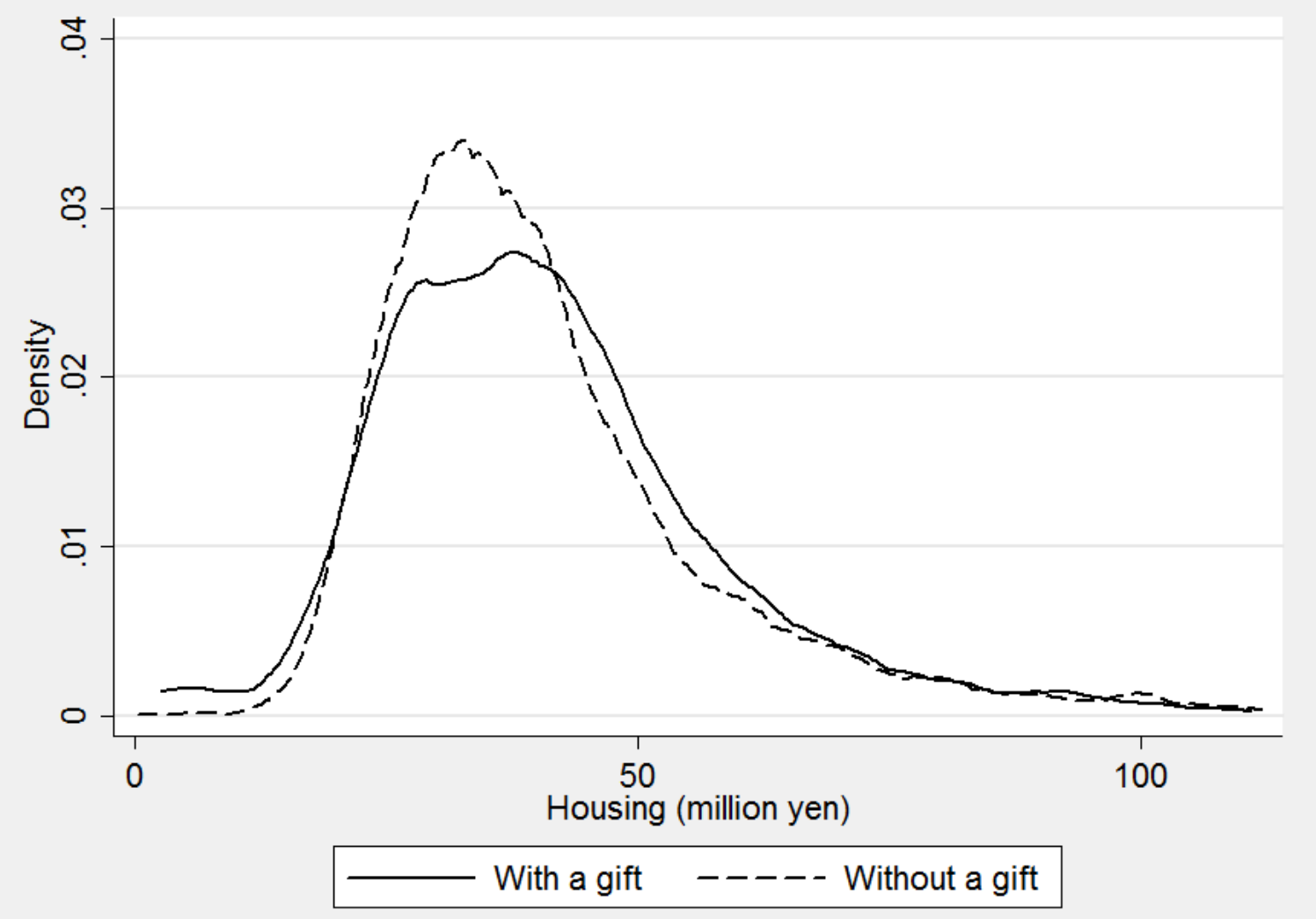

Fig. 1: Kernel densities of home value 